\title{
Da construção e reprodução do conhecimento e discurso médicos. Para uma etnografia da transplantação hepática
}

On the construction and reproduction of medical knowledge and discourse.

Towards an ethnography of hepatic transplants

De la construction et de la reproduction de la connaissance médicale et de son discours. Pour une ethnographie de la transplantation hépatique

\section{Helena Serra}

\section{OpenEdition}

\section{Journals}

Edição electrónica

URL: https://journals.openedition.org/rccs/731

DOI: $10.4000 /$ rccs.731

ISSN: 2182-7435

\section{Editora}

Centro de Estudos Sociais da Universidade de Coimbra

Edição impressa

Data de publição: 1 dezembro 2007

Paginação: 113-131

ISSN: 0254-1106

Refêrencia eletrónica

Helena Serra, «Da construção e reprodução do conhecimento e discurso médicos. Para uma etnografia da transplantação hepática», Revista Crítica de Ciências Sociais [Online], 79|2007, publicado a 01 outubro 2012, consultado a 21 setembro 2021. URL: http://journals.openedition.org/rccs/731 DOI: https://doi.org/10.4000/rccs.731

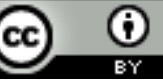




\section{Da construção e reprodução do conhecimento e discurso médicos. Para uma etnografia da transplantação hepática}

Partindo de alguns contributos contemporâneos da área da sociologia médica, apresentam-se alguns resultados de uma investigação de natureza etnográfica numa unidade de transplantação hepática. Elegeu-se uma metodologia qualitativa, tendo como técnica central de recolha de informação a observação participante e continuada e, como técnica complementar, entrevistas semi-estruturadas e aprofundadas, aplicadas às várias categorias representadas no terreno de observação. Começa-se por estabelecer a distinção entre os vários tipos de conhecimento, evidenciando a primazia da experiência clínica em relação ao conhecimento teórico na construção do conhecimento médico; abordam-se ainda os discurso(s) e prática(s) médicas, a propósito da construção do diagnóstico; finalmente, e a encerrar a discussão, é focada a questão da incerteza na construção do conhecimento médico.

\section{Introdução}

Nas abordagens sociológicas contemporâneas, poder e conhecimento assumem uma relação profunda, particularmente nos mais recentes trabalhos do construtivismo social que evidenciam as relações entre conhecimento e discurso na construção de estratégias de poder. A construção social do conhecimento e da realidade constituiu igualmente o foco da linha da fenomenologia do pensamento sociológico, popularizada por Berger e Luckman nos finais da década de 60. Berger e Luckman (1967) argumentam que o conhecimento é produzido de forma criativa por indivíduos e é orientado para problemas práticos particulares.

A partir desta perspectiva, inúmeros trabalhos acerca da natureza do conhecimento médico têm surgido. Nesta esteira, que se constitui enquanto desafio à ideia moderna de racionalidade científica, por vincular a produção de conhecimento aos poderes e aos seus discursos, procura-se identificar os diversos conhecimentos que são produzidos e desenvolvidos no contexto dos cuidados médicos. Esta perspectiva contrasta com a visão tradicional da medicina que encara a doença como estando localizada num corpo 
enquanto objecto físico, e que pode ser objectivamente identificada e tratada como condição fisiológica a partir do conhecimento médico científico.

Neste artigo, apresentam-se alguns resultados de uma investigação de natureza etnográfica, em torno da construção e reprodução do conhecimento e discurso médicos. Partindo de alguns contributos contemporâneos da área da sociologia médica, particularmente do construtivismo social e daquilo que se designa por abordagem foucaultiana, procura-se identificar numa unidade de transplantação hepática (UT), os modelos de construção e reprodução do conhecimento e discurso médicos, analisando como estes dois elementos são reconstruídos em termos estratégicos. Entre outros contributos, os trabalhos de Freidson (1984, 1986, 1987) constituem um suporte importante para a análise das dimensões presentes no trabalho médico. Destacam-se também os trabalhos de Turner (1995) e os de Atkinson (1977, 1995), já que ambos evidenciam a centralidade do discurso médico, que assenta na interacção entre o trabalho médico e as tecnologias, bem como as relações entre o conhecimento, o discurso médico e o contexto das práticas médicas. Elegeu-se uma metodologia qualitativa que inclui a utilização de diferentes técnicas de recolha de informação, tendo-se optado por uma técnica central e outras técnicas complementares. Neste sentido, elegemos como técnica central de recolha de informação a observação participante e continuada e, como técnica complementar, entrevistas semi-estruturadas e aprofundadas, aplicadas às várias categorias representadas no terreno de observação.

O contexto de pesquisa, uma unidade hospitalar de transplantação hepática, surge como uma das áreas mais sofisticadas da medicina, quer pela tecnologia e as respectivas práticas médicas que implica, quer, também, pela natureza multidisciplinar que necessariamente a caracteriza. A grande complexidade da prestação dos cuidados encerra aspectos muito precisos da organização e divisão do trabalho que decorrem da hiper-especialização médico/cirúrgica que envolve a produção dos cuidados de saúde neste serviço. Estamos num terreno caracterizado pela presença do exercício de diversos poderes que vão sendo constantemente construídos e reconstruídos no exercício e no cruzamento das práticas médicas das diferentes especialidades envolvidas, cada uma delas subordinada a um esquema próprio de organização, tão específico quanto as práticas médicas que as distinguem. Nesta etnografia, os médicos assumem um papel central, sendo que, neste artigo, seleccionaram-se os lugares que nos permitiram observar o trabalho das especialidades médicas de hepatologia, cirurgia e anatomia patológica.

Assim, começamos por estabelecer a distinção entre o conhecimento teórico e o conhecimento adquirido através da experiência no terreno das 
práticas médicas, evidenciando a primazia da experiência clínica em relação ao conhecimento teórico na construção do conhecimento médico; abordam-se ainda os discurso(s) e prática(s) médicas, a propósito da construção do diagnóstico; finalmente, e a encerrar a discussão, é focada a questão da incerteza na construção do conhecimento médico.

\section{Entre a teoria e a prática da medicina: o primado da experiência clínica na construção do conhecimento médico}

Tal como em qualquer outra área da medicina, na transplantação hepática o conhecimento médico constitui propriedade emergente da interacção entre as diferentes especialidades médicas. A prática clínica encerra procedimentos que atravessam a actividade médica estando os processos de produção do conhecimento e de formação de opinião dispersos no tempo e no espaço.

A noção de conhecimento está profundamente ligada à ideia de competência, sendo por isso importante perceber como estas noções se interligam nas práticas médicas quotidianas. Mas importa não esquecer que cada especialidade encerra em si conhecimentos e competências próprias que, no conjunto das interacções, constroem um património de conhecimentos comuns, traduzidos em competências.

A propósito das referências básicas das noções de trabalho e competência, podemos afirmar que se trata manifestamente de um corpo de factos ordenados por determinadas ideias abstractas ou teorias que se encontram materializadas nos tratados e nos manuais (Freidson, 1984). Estas fornecem a substância formal daquilo que os especialistas aprendem nas suas escolas e que é considerado como conhecimento. Esse conhecimento ou competência é, pois, extremamente limitado enquanto realidade; ele está encerrado nos livros ou nos cérebros e, definido nestes modos, parece não ter qualquer ligação com as práticas médicas. Neste sentido, Freidson (1984) chama a atenção para a absoluta necessidade de redefinir a noção de conhecimento, estabelecendo a correspondência entre o "saber" e o "fazer".

Avançando nesta linha, podemos distinguir os que se consagram ao desenvolvimento de um corpo de conhecimentos daqueles que os aplicam. Trata-se de distinguir o corpo dos conhecimentos enquanto tal das actividades humanas que consistem em criar esse conhecimento (investigação e pesquisa) e em aplicá-lo (a prática). Podemos avaliar estas actividades de acordo com a sua fidelidade em relação ao conhecimento, i.e., tentar perceber em que medida as práticas médicas se fundam no conhecimento teórico. Assim, para avaliar o especialista e a sua competência, não avaliamos apenas o conhecimento da sua disciplina enquanto tal, mas também as relações entre 
a sua actividade de especialista e o respectivo conhecimento. A este propósito, Keating e Cambrosio (2003: 27) introduzem a noção de plataformas biomédicas, que permite clarificar as práticas e a organização do trabalho nas ciências biomédicas. Estas plataformas constituem arranjos quer de natureza material, quer de natureza discursiva, que permitem criar a base de organização das práticas médicas.

Em oposição ao conhecimento médico, na medicina enquanto tal, encontram-se todas as práticas que se desenvolvem a partir do momento em que esse conhecimento é aplicado a doentes e contextos concretos. O conhecimento médico "puro" é transformado, mesmo manchado, no decorrer da sua aplicação. De facto, este conhecimento não pode continuar "puro", pelo contrário, deve organizar-se socialmente em práticas, já que o conhecimento médico se concretiza através das suas utilizações. Mas o mais importante tem a ver com facto de o médico estar moralmente comprometido a intervir, mesmo na ausência de conhecimento seguro, na medida em que a medicina é, por definição, uma actividade de consulta e de prática, mais do que uma actividade científica e erudita (Freidson, 1984). No caso da unidade de transplantação, ao observarmos algumas situações onde são discutidos casos mais polémicos, assistimos, por parte de alguns médicos e cirurgiões, à utilização de argumentos que se prendem mais com questões morais do que com critérios científicos. Em algumas situações em que a indicação de transplante é, do ponto de vista médico-científico, inequivocamente desaconselhada, assistimos ao apelo do dever moral para justificar o transplante. Expressões como "é um homem novo e saudável, com porte atlético" ou "tem apenas vinte e quatro anos e uma filha pequena, é impossível recusar-lhe uma oportunidade como esta", são utilizadas estrategicamente no diálogo entre médicos. Em algumas situações, quando questionados sobre determinados casos concretos, vários médicos referiram que, numa ou noutra situação, "o transplante foi efectuado porque, apesar de medicamente não dever ter sido realizado, moralmente tiveram de o fazer" (nota de trabalho de campo).

Neste sentido, o conhecimento prático da medicina assenta, em grande parte, na experiência clínica e pessoal dos médicos. O seu conhecimento científico provém, na realidade, e em grande medida, das descobertas individuais realizadas por clínicos. Por isso, o próprio modelo que está subjacente à prática médica encoraja o médico a desviar-se individualmente do conhecimento codificado, apoiando-se em observações individuais, feitas em primeira mão, sobre casos concretos. Estamos a falar, de acordo com Freidson (1984), de "juízos" ou mesmo de "sabedoria", já que o médico insiste na primazia da sua experiência pessoal e na liberdade de escolha de 
acção fundada sobre essa experiência encorajada pela ideologia da medicina. Trata-se, precisamente, de uma ênfase inversa à que ocorre na ciência acerca do conhecimento tornado comum, recolhido e verificado graças a métodos que têm como objectivo ultrapassar as deficiências da experiência individual. O saber prático, em primeira mão, é, assim, muitas vezes designado por "sabedoria" e representa o condensar da experiência de toda uma vida.

Alguns dos médicos e cirurgiões da UT enquadram-se precisamente neste perfil. Para além do director da unidade, que constitui uma referência relativamente a experiência acumulada e pioneirismo nesta área da medicina, outros elementos da equipa destacam-se no domínio de técnicas específicas, no caso dos cirurgiões, ou de determinadas patologias, no caso dos hepatologistas. Esse domínio tem origem na própria experiência individual de cada um dos sujeitos. Nesta entrevista, vemos referida a importância da experiência clínica na construção do conhecimento médico. No caso da UT, esta experiência acumulada tem vindo a permitir a este serviço conquistar um lugar de referência no panorama mundial da transplantação hepática:

Há, com certeza, coisas novas. Primeiro, há um aperfeiçoamento de dados base, há experiência adquirida, há uma curva de aprendizagem que, enfim, decorreu. Neste momento estamos a uma velocidade de cruzeiro e pouco aprendemos mais a partir de agora no que diz respeito à prática diária, à prática, digamos, rotineira. (HEPATOLOGISTA, 12)

A experiência clínica é tão fundamental na transplantação que o lançamento do Programa de Transplantação Hepática, na UT, foi antecedido por alguns anos de cirurgia experimental, num laboratório criado no hospital, exclusivamente para o efeito. Neste biotério, anestesistas e cirurgiões com larga experiência nas respectivas áreas de especialidade, mas ainda não na transplantação hepática, praticavam em porcos as várias técnicas de transplantação do fígado.

Ainda a propósito da importância da experiência clínica na formação dos médicos que constituem a equipa de transplantação hepática, sobretudo dos mais antigos ou pioneiros desta área em Portugal, verificamos que frequentaram estágios em centros no estrangeiro por forma a aprenderem não apenas o conhecimento teórico, mas, sobretudo, experiência clínica. Trata-se, não apenas de aprender com a experiência dos outros, mas, sobretudo, de ver como os outros praticam e praticar com eles.

Temos, assim, duas componentes essenciais na construção do conhecimento médico, a teoria e a prática clínica. No entanto, a propósito da natureza do 
trabalho médico, Freidson (1984) refere que este é pouco teórico, já que se trata sobretudo de um trabalho de aplicação, diferindo, deste modo, do trabalho de investigação. As especialidades clínicas devem, na maioria dos casos, utilizar os princípios gerais para controlar problemas concretos. Pelo contrário, o investigador parte da investigação de fenómenos concretos para verificar, elaborar ou encontrar princípios gerais. Na medida em que a prática médica faz tão pouco uso da ciência, esta utilização obedece a uma orientação característica: ela esforça-se por aplicar, mais do que criar ou contribuir. Se o trabalho médico se concentra em problemas concretos e na sua solução prática, é importante que ele prossiga mesmo quando lhe faltam fundamentos científicos, na medida em que este trabalho assenta sobre a intervenção e é independente da existência de conhecimentos confirmados. Assim, o médico sente-se mais seguro e tranquilo quando procede em situações de quase incerteza, ou que ultrapassam mesmo as regras científicas, do que em situações onde pura e simplesmente nada faz. Foi possível observar vários exemplos concretos na transplantação hepática, sobretudo no que diz respeito à atitude dos cirurgiões em face de doentes polémicos, relativamente aos quais, cientificamente, não existe qualquer indicação para transplante. Mesmo nestas situações, os cirurgiões estão dispostos a correr riscos, na medida em que, no seu entender, mais arriscado será nada fazer.

A estes aspectos é ainda importante acrescentar que a prática médica diz respeito, acima de tudo, a situações individuais, procedendo pouco de acordo com aspectos estatísticos ou de conjunto. Este tipo de dados é utilizado quando serve apenas como referência para determinar a natureza de um caso específico. Mesmo quando se dispõe de conhecimentos científicos gerais, o simples facto de as variações individuais colocarem constantemente o problema da estimativa torna necessária a realização de exames pessoais e directos em cada caso individual. Como refere um dos hepatologistas, "não existem doenças, mas sim doentes" (nota de trabalho de campo).

A propósito da importância do risco e da tomada de decisão que estes aspectos implicam, Freidson (1984) refere que o risco e os juízos formulados podem variar consideravelmente consoante as situações concretas. No entanto, existe um aspecto que jamais varia: o facto de se tratar de um trabalho de aplicação que implica a intervenção do médico, seja qual for o estado de conhecimento, e que pressupõe a existência de um elemento central - a experiência directa de casos individuais. Em várias ocasiões, foi possível constatar que alguns doentes, imediatamente antes de tomarem contacto com a UT, tinham como referência um dos elementos da equipa. É o caso de um doente que teve conhecimento do serviço por via de um dos cirurgiões que procurou por sua iniciativa, na medida em que era 
reconhecido pela opinião pública como um dos médicos mais experientes na área do transplante hepático. A importância da experiência clínica é, de facto, fundamental também do ponto de vista da opinião pública. De uma forma geral, os médicos, e os serviços a que estão associados, são reconhecidos pelo número de casos tratados, pelos resultados que apresentam e pelos anos de experiência em áreas específicas de intervenção, tal como é referido nesta entrevista.

Não adianta ter um centro que transplante uma ou duas crianças por ano. Eu, como pai, não vou dar a transplantar o meu filho a pessoas que fazem um ou dois transplantes por ano. Vou a outro centro que tenha uma casuística muito maior, está a perceber. As Unidades só se tornam boas quando fazem muitos, quando têm experiência. Aqui ninguém é iluminado. (CIRURGIÃO, 8)

Estes factores que caracterizam o trabalho médico quotidiano parecem ser responsáveis pelas atitudes que limitam o sentido de responsabilidade, dando-lhe contornos especiais. O médico é conduzido a valorizar a sua responsabilidade individual em detrimento de uma responsabilidade colectiva, levando, por outro lado, a poucos esforços no sentido de fazer respeitar as normas profissionais de eficácia. Do mesmo modo, esta situação conduz à valorização da primazia da experiência clínica directa sobre as leis científicas ou as regras gerais, acentuando-se a diversidade de opiniões definidas como aceitáveis e permitindo resistir, de consciência tranquila, a eventuais críticas provenientes dos seus pares.

Num trabalho acerca dos estudantes de medicina na década de 60, Becker et al. (1961) referem que, durante os anos de formação, são incutidos nos futuros médicos padrões de comportamento orientados de acordo com duas normas decisivas - a responsabilidade e a experiência. O termo "experiência” refere-se à experiência clínica, à experiência real em lidar com os doentes e a doença, sendo que o seu significado assenta na sua polaridade implícita na "aprendizagem através dos livros" (book learning). A experiência clínica implícita neste termo dá ao médico o conhecimento necessário para tratar os seus doentes com sucesso, mesmo que esse conhecimento ainda não tenha sido sistematizado e comprovado cientificamente. $O$ médico não adquire este conhecimento através do estudo, mas sim através da observação do fenómeno clínico que lhe permite lidar com problemas clínicos. A experiência clínica pode mesmo chegar a substituir o conhecimento cientificamente comprovado e ser utilizada para legitimar a escolha de procedimentos e para eliminar a utilização de outros que estão cientificamente estabelecidos (Becker et al., 1961). 
No decorrer desta investigação, assistimos a diversas situações em que a opção pelo transplante acaba por ser justificada com base na experiência clínica deste serviço, fazendo quase tábua rasa do conhecimento cientificamente comprovado pela literatura. Como refere um dos cirurgiões, "dada a qualidade do serviço prestado por esta unidade de transplantação, cujos resultados falam por si, podemos ter lugar para excepções" (nota de trabalho de campo).

Esta ideia assenta no facto de que o médico, para elaborar o seu diagnóstico, deve ainda utilizar directamente os seus sentidos, que devem ser treinados na prática, o que quer dizer que o conhecimento livresco e científico, em face das contingências práticas e da complexidade dos casos individuais, não é suficiente. Seja qual for o motivo, a experiência tem primazia na formação médica. O trabalho de Becker et al. (1961) mostra que a ideia de experiência clínica organiza a escolha dos estudantes de medicina, na medida em que estes consagram o máximo de esforços à acumulação de experiências práticas, em detrimento de conhecimentos abstractos.

Também Freidson (1984) estabelece uma comparação entre médicos que praticam a clínica e teóricos e investigadores. Assim, e em primeiro lugar, o autor refere que o objectivo dos primeiros é sobretudo a acção e não tanto o conhecimento, pretendendo agir com sucesso. Mesmo que o fruto da sua acção não seja positivo, ainda assim é preferível agir a não fazer nada. A acção transforma-se num fim em si mesmo. Nesta linha surge, em segundo lugar, aquilo que Freidson designa por "acreditar no que faz". O clínico acredita, de uma forma geral, que a sua intervenção faz sempre mais bem do que mal. Ele próprio reage como perante um placebo, na medida em que o seu trabalho se processa em torno de uma série de problemas concretos e individuais. O sucesso que o premeia e a causa que o determina raramente são equívocos. Uma vez embrenhado na acção, o clínico, por vezes confrontado com o erro, é levado a manifestar uma certa vontade em acreditar no valor daquilo que faz. Em terceiro lugar, seja devido a esta orientação para a acção, seja pela complexidade e pela diversidade dos casos concretos, o clínico é sobretudo um indivíduo pragmático, mais fiel aos resultados concretos do que, propriamente, à teoria. Em quarto lugar, enquanto clínico, o médico aprendeu a acreditar que o tempo ajuda e que pode confiar na acumulação da sua experiência directa e pessoal, no subjectivismo, deixando para segundo plano os princípios abstractos, sobretudo quando se trata de avaliar e tratar os aspectos do seu trabalho que não revelam automatismos. Finalmente, o médico clínico acentua, de forma consciente, o peso da indeterminação ou incerteza, sem perder tempo com questões de regularidade ou de comportamento científico. Que este aspecto 
possa ou não significar ignorância nos domínios do conhecimento e da técnica disponíveis, não é relevante; o que importa salientar é que a incerteza proporciona ao médico o terreno psicológico que lhe permite justificar a importância pragmática que concilia com a experiência directa.

Mesmo assim, na UT, as especialidades médicas observadas consideram fundamental a componente de investigação, evocando a dificuldade em conciliar a investigação com a prática clínica, pelas características dos próprios hospitais e respectivos serviços, que influenciam as formas através das quais o conhecimento médico se reproduz. Neste sentido, a vocação desta unidade hospitalar, sobretudo ligada à prestação dos cuidados médicos e não à investigação, condiciona as formas de reprodução do conhecimento, que é predominantemente construído na prática clínica da prestação dos cuidados médicos.

As responsabilidades assumidas pelo médico em relação aos actos que pratica tornam-no, necessariamente, vulnerável. No caso particular da transplantação hepática, esta questão assume de facto um enorme peso. Em inúmeras ocasiões observámos que, se, por um lado, são gratificantes as situações em que o médico é reconhecido por ter sido bem sucedido, do mesmo modo pode incorrer em situações de reprovação em circunstâncias opostas. Assumir a responsabilidade de uma prática concreta, seja qual for, implica correr riscos. A confiança depositada na experiência clínica pessoal tem um grande peso, de tal forma que o médico acaba por privilegiar a autoridade das suas faculdades sensoriais, libertando-se ao mesmo tempo da hegemonia presente na tradição ou na ciência. Em última instância, é a ciência e apenas ela que guia os seus actos, mesmo quando os resultados esperados não são alcançados. Muitas vezes, o médico recusa-se a modificar a sua táctica com base em considerações estatísticas ou abstractas. Ele precisa de ver e de sentir por si mesmo. Sobretudo, necessita de tentar salvar vidas através do último dos recursos possíveis, o transplante.

Podemos então distinguir racionalidade clínica de racionalidade científica. Assim, a primeira é singular e técnica, constituindo um todo, uma espécie de classificação com imensos detalhes que provêm dos casos individuais. A grande diferença entre estes dois tipos de racionalidades é que a primeira não constitui um instrumento destinado a explorar ou a descobrir princípios gerais, como é o caso do método científico, constituindo antes um instrumento destinado apenas a separar e a estabelecer interconexões entre os factos que o médico percebe e aqueles que ele coloca como hipóteses. Assim, os princípios constroem-se no decorrer da prática, mas trata-se de generalizações a partir da experiência clínica, i.e., de uma experiência pessoal. 


\section{Discurso(s) e prática(s) médicas. A construção do diagnóstico}

Nas práticas médicas, a utilização de vocabulário específico ou linguagem científica acerca da doença, parece reforçar estratégias particulares que deixam adivinhar determinados conflitos de interesses. Nestas interacções, os médicos comunicam informações técnicas específicas que dizem respeito a casos específicos. Através do discurso utilizado, constatamos a existência de um monopólio de competências e conhecimentos especializados que sustentam a base do exercício da profissão por parte destes médicos, possibilitando-lhes a posse de um estatuto próprio no interior do grupo, que se traduz no poder de tomar decisões concretas no que diz respeito ao percurso da doença. Deste modo, a autoridade do médico, por exemplo numa consulta, depende da extensão considerável do seu monopólio de conhecimento.

A propósito do trabalho de diagnóstico, Atkinson (1981) refere-o como um campo de manifestações que devem ser interpretadas por forma a produzir um quadro de diagnóstico que permita atribuir um rótulo credível à doença. A retórica convencional da prática médica apresenta dois tipos de dados disponíveis que se referem a sinais e sintomas. No entanto, estes aspectos relacionados com a doença, ao contrário do que possa parecer à partida, estão relacionados com aspectos subjectivos de interpretação dos sinais e sintomas, opondo-se ao que muitas vezes é assumido como factores objectivamente observáveis da doença.

Neste sentido, interessa analisar estes procedimentos interpretativos, a forma como os médicos falam dos sinais objectivos da doença, construindo desta forma o seu diagnóstico. Na linha de Foucault, podemos referir que tudo aquilo que num determinado momento pode parecer claro não o foi certamente noutros momentos da história da medicina. Também determinados aspectos que se apresentam óbvios para determinados indivíduos que pertencem a determinada cultura não o são para outros. Assim, a dimensão histórica dos "olhares" é ilustrada por Foucault (1963). O autor utiliza o contraste entre duas descrições clínicas por forma a ilustrar a mudança fundamental associada ao nascimento da clínica. Esta mudança depende da alteração das formas de percepção, o que quer dizer que a relação entre o visível e o invisível altera a sua estrutura que é revelada a partir do gaze e da linguagem. Também Mol (2002) refere a relação entre estes "múltiplos conhecimentos", tecnologias, percepções da doença e a prática médica. A par da observação das práticas médicas em torno do diagnóstico e tratamento da aterosclerose, a autora analisa o discurso do doente em torno da doença, reflectindo sobre uma multiplicidade de olhares sobre a mesma. Do mesmo modo, a respeito do diagnóstico, Atkinson (1981) compara esta 
fase do trabalho médico ao trabalho de detective. As tarefas de construção da história clínica, observação, análise da informação disponível, proveniente de diversas fontes, são, assim, comparadas a todo um trabalho de reconstrução em que o médico aplica a famosa técnica de detecção. Este método está, sobretudo, associado às especialidades médicas. Por exemplo, a construção do conhecimento médico que ocorre nos laboratórios de anatomia patológica revela-se como um dos exemplos mais elucidativos do clinical gaze de Foucault. A importância dos vários olhares sobre uma realidade que não se apresenta de uma forma evidente à partida, ajuda a construir as várias hipóteses através de um método de observação rigoroso, no qual a intuição e a dedução se misturam numa espécie de exercício permanente em que a teoria e a prática se fecundam mutuamente.

$\mathrm{Na}$ transplantação hepática, como refere um dos anatomo-patologistas, a abordagem é um pouco subjectiva, o que implica a presença de vários olhares que observam o mesmo fenómeno de diferentes ângulos. Em todo este processo, a presença de outros conhecimentos para além do dos anatomo-patologistas, nomeadamente das especialidades clínicas, é fundamental. A este propósito, como referem Keating e Cambrosio (2003: 39), é interessante observar de perto a ligação entre estas actividades de plataforma e as actividades clínicas, já que a estrutura hospitalar não está simplesmente organizada em torno de plataformas técnicas; estas redefinem as práticas clínicas e fazem-no incorporando o conhecimento biomédico. Deste modo, as plataformas técnicas levam à transformação das relações entre a biologia e a clínica, permitindo a redefinição da organização e conteúdo do trabalho em medicina (Keating e Cambrosio, 2003: 43). No caso da UT, é sobretudo nos casos mais polémicos, nomeadamente nas rejeições do novo órgão transplantado, que a presença do hepatologista é imprescindível, não apenas pelo conjunto de informações que domina acerca do doente, mas também pelos seus vastos conhecimentos e experiência nas áreas específicas do fígado, que corresponde a um olhar necessariamente diferente sobre o fenómeno, absolutamente essencial para, em conjunto com o anatomo-patologista, concluir acerca do caso em questão.

Se aparece uma biopsia [...] nós as três vemos, porque é melhor vermos as três do que uma só. Porque em anatomia patológica há muito isto, para um maior rigor de observação. Nós fazemos sempre o controlo com mais de um observador e às vezes é muito importante... em certos casos, muitos casos difíceis... temos de ter uma formação teórica e prática. Mas a abordagem é um bocado subjectiva... tem algo de subjectivo, não é... Não é só aquilo que se está a ver [...] é tipo um raciocínio detectivesco, é passo a passo como o Sherlock Holmes. Quer dizer, vamos ver dali, vamos 
ver de acolá, e passo a passo chegar a... e depois isto tudo não pode ser feito isoladamente só com etiologia, tem de ser em simbiose com os dados clínicos... Não podemos interpretar sem ter um apanhado clínico de todos os dados do momento, do doente. Portanto, se não está completo, temos de completar com o nosso colega que nos pediu ... e muitas vezes esclarecemos muito. Ainda ontem, olhe foi ontem, era um caso difícil que o hepatologista me mandou. E depois ao falar com ele eu disse-lhe assim: "Olhe, tem uma rejeição muito ligeira, mas eu até me apoiei mais porque vi aí as análises" e ele disse assim: "Olha, é que ela teve uma reacção anterior, portanto”. E eu até me estava a apoiar numa coisa... mas eu não sabia que ela tinha tido. Note que tudo isto leva a interpretar e é preciso sabermos tudo o que se passa ao lado... (ANATOMO-PATOLOGISTA, 26)

Por outro lado, de acordo com a visão das especialidades médicas não cirúrgicas, relativamente ao diagnóstico, as áreas cirúrgicas são encaradas de uma forma mais limitada, nos termos da qual o trabalho do cirurgião é, intelectualmente, e mesmo na prática, mais restrito. No trabalho de Atkinson (1981), os contrastes da medicina criam um estereótipo de acordo com o qual as tarefas de diagnóstico, no cirurgião, exigem menos em comparação com as dos médicos. O cirurgião tem de ser mais preciso na identificação de uma situação aguda abdominal, podendo então avançar e abrir. O cirurgião pode, assim, lidar directamente com o problema, enquanto o médico tem de trabalhar à distância, ficando pela dedução clínica. Em último recurso, o cirurgião pode confirmar as suas dúvidas através da observação directa.

Talvez por estes motivos, os hepatologistas referem-se muitas vezes aos cirurgiões como mais técnicos, por executarem um "trabalho de mãos" (na UT, o termo "homens do talho" é, de um modo geral, atribuído aos cirurgiões), oposto a um trabalho mais intelectual dos médicos. Da mesma forma, é atribuído aos cirurgiões um trabalho em torno de doenças específicas e localizadas, enquanto os problemas da medicina são, na maioria, mais gerais e difusos, exigindo muito em termos de agudeza de espírito por parte do médico. Numa ocasião em que trocávamos algumas impressões com um dos hepatologistas acerca de um doente transplantado, este médico referia a incapacidade dos cirurgiões em avaliarem os doentes a partir de técnicas que não as cirúrgicas: "eu consegui ver qual era o problema através do TAC e eles, mesmo abrindo, tiveram dúvidas" (nota de trabalho de campo).

Obviamente que a visão do cirurgião acerca da sua especialidade é bem diferente. Como podemos constatar a partir da observação, a grande maioria dos cirurgiões não se encaixa neste estereótipo, muito pelo contrário. O cirurgião encara a prática da cirurgia como intelectualmente estimulante. 
Aliás, o próprio acto médico em torno da cirurgia, com todo o aparato cirúrgico do bloco operatório, a par dos grandes momentos de tensão, dá à cirurgia um charme próprio ou, como refere Atkinson (1981:32), "a glamour all of its own".

De facto, a importância da experiência médica faz-se sentir de uma forma particular na especialidade de cirurgia, na qual a expressão "há que ganhar mão", muitas vezes utilizada pelo cirurgião, ilustra o peso desta componente na construção do conhecimento médico nesta especialidade, que, aliás, é caracterizado por uma forte componente de equipa, ao contrário do que se passa em relação aos hepatologistas, para quem a construção do conhecimento médico é individual.

O peso que a experiência clínica tem na formação das competências médicas é ainda mais acentuado na especialidade de cirurgia. Se a este aspecto acrescentarmos o facto de estarmos perante uma área cirúrgica das mais sofisticadas, mais reforçada e determinante será a absoluta necessidade de um treino cirúrgico que pressupõe muitas horas de prática. Os exemplos nesta investigação são, aliás, muito elucidativos.

Com experiência evidentemente. Fundamentalmente esse conhecimento é... ganho no dia a dia... É no dia a dia que se aprende. E é com determinada situação que é apresentada, que o doente apresenta... (CIRURGIÃO, 10)

A propósito da formação dos cirurgiões mais novos, um dos mais jovens membros da equipa refere a oportunidade que é dada aos internos de cirurgia, logo nos primeiros anos, de poderem praticar a cirurgia de transplante com os seus tutores, o que testemunha a importância fundamental da experiência cirúrgica.

Aqui o que a gente ganha em termos científicos é um pouco aquilo a que as pessoas chamam experiência e é isso. Uma experiência é conhecimento científico... A gente chama-lhe é outra coisa. (CIRURGĨ̃O, 2)

Não se pode vir só ao transplante duas vezes por ano; quem quiser tem que vir, tem que dar mesmo o litro, porque para aprender tem que dar o litro. E não é compatível com vir só uma ou duas vezes por mês ou de três em três meses... Não! Não é compatível, tem que vir [...] e sacrificar a vida familiar, sacrificar o tempo livre, sábados, domingos, feriados, e nem toda a gente está disposta a isso. (CIRURGIÃO, 5)

Nesta entrevista, a propósito da falta de internos de cirurgia interessados no transplante, um dos cirurgiões refere a importância da transmissão do 
conhecimento para os mais novos a partir da prática cirúrgica que é fundamental na formação de um cirurgião. Mesmo no caso dos internos de cirurgia que não têm, necessariamente, a ver com o transplante hepático, a oportunidade de aprender a partir da sua presença numa operação de transplante ou de colheita constitui uma mais-valia extremamente importante para a aquisição de conhecimento.

Para a cirurgia geral, é o supra-sumo da cirurgia geral. Para o aluno... nós trazemos, os alunos têm que vir connosco, e eles querem muito e nós fazemos e temos a noção que estamos a investir no futuro. Porque há muitos alunos que estão a gostar muito do transplante e a achar muito interessante, portanto, estamos a colocar o bichinho da transplantação. [...] Dizemos: "Vocês deviam ir ao transplante, aquilo realmente é óptimo para vocês" [...] Nós tentamos imenso que isso se passe e que as pessoas vão connosco e tentamos puxar as pessoas a ir connosco. Mas realmente vemos que de cada dez que nós, entre aspas, chateamos para virem, há um que vem, ou há dois que vêm. E desses dois há um que fica, que gosta e que realmente ... não pode ser mais interessante. Agora, é aquela que se calhar dá mais nas vistas, percebe? O transplante!! Uma sala muito grande, com muita gente lá dentro, com muita aparelhagem com muito ... muitas horas. (CIRURGIÃO, 4)

No caso dos hepatologistas, para além dos aspectos referidos a propósito da produção de conhecimento médico na construção do diagnóstico clínico, a experiência clínica assume igualmente um papel de relevo.

[...] A pessoa não sabe fazer CPRE's ${ }^{1}$ se não tiver aprendido a fazer endoscopias, e endoscopias provavelmente não tem nada. Portanto, há todo um caminho que é preciso percorrer para que depois se possa dar apoio à parte hepatológica, especificamente. Mas para isso é preciso uma formação prévia. Por isso é que as coisas devem ser mais gerais, digamos, mais ... A partir de uma determinada altura, então a parte tecnológica quem não pratica não... não faz pura e simplesmente. Não sabe... (HEPATOLOGISTA,13)

\section{Conhecimento médico, experiência clínica e incerteza}

No contexto da medicina, o conhecimento médico tem estado associado à noção de "experiência clínica" e garantido pelo privilégio do clinical gaze (Foucault, 1963). Este aspecto veio consolidar a centralidade da "aprendi-

\footnotetext{
${ }^{1}$ Colangio-pancreaticografia retrógrada endoscópica (CPRE). Trata-se de uma endoscopia pancreática e biliar que, associada à tecnologia de ultra-sons, proporciona a resolução de imagens de alta qualidade.
} 
zagem na prática da clínica" como forma de transmissão cultural do conhecimento. Apesar da fragmentação do conhecimento médico e do seu ensino, do desenvolvimento crescente de especialidades e da crescente importância da ciência e da tecnologia, o "ensino na prática da clínica" continua a assumir uma importância central. Assim, não obstante as alterações teóricas e práticas da educação e formação de médicos, o ensino das práticas médicas tem permanecido, no seu essencial, inalterado. A sua justificação reside naquilo que Foucault identifica, desde os primórdios da medicina, como um apelo à experiência directa e pré-teórica e à acumulação de experiência clínica pessoal.

A importância crucial da experiência é muitas vezes relacionada com um conjunto de factores referidos como "incerteza". Freidson (1984) assinala a questão da incerteza no conhecimento, sugerindo que o conhecimento e a experiência pessoal ou individual contrastam com as noções de previsibilidade e regularidade. A este propósito, Atkinson (1981) refere a questão do dogmatismo, apresentando este termo não em oposição à noção de conhecimento pessoal, mas como parte da mesma perspectiva da experiência individual. $\mathrm{O}$ médico que apela ao seu conhecimento individual fá-lo, não por referência à sua incerteza, ou à incerteza dos seus colegas, mas baseando as suas acções e decisões naquilo que se pressupõe consolidado, i.e., a certeza proveniente da experiência directa confirmada e reconfirmada. $\mathrm{O}$ apelo constante à experiência é aceite para criar conhecimento acerca da regularidade e da estabilidade. O médico pratica na condição da certeza pessoal, seguro da sua própria experiência, tal como sugere Atkinson (1981) quando refere que o apelo à experiência é assumido por forma a prover conhecimento da regularidade e estabilidade, sendo que a ordem é assumida para ser inerente ao fenómeno e aberta ao gaze, em vez de residir em sistemas de teoria. A "clínica" é, portanto, tomada para prover às demonstrações incontestáveis da realidade na percepção directa das suas regularidades. O clínico não está, portanto, a operar num estado de "incerteza", mas antes a operar numa garantia segura através da experiência.

O conhecimento médico é, deste modo, produzido com base na experiência. No fundo, trata-se daquilo que Freidson (1984: 171) designa por mentalidade clínica. Tendo de confiar constantemente na sua experiência pessoal, em casos concretos e individuais, o médico acaba por confiar essencialmente na autoridade dos seus próprios sentidos, independentemente da autoridade da tradição ou da ciência. Deste modo, o médico apenas pode actuar com base naquilo que ele próprio experimentou, sobretudo quando os resultados da sua prática são positivos. 
Assim, o carácter intuitivo na percepção da doença, que pouco tem a ver com questões científicas, é testemunhado pelos médicos com longa experiência clínica. Quanto a este ponto, é de referir o excerto de entrevista em que apenas o director da UT e o coordenador das equipas de anestesia e intensivismo apoiam a decisão do coordenador dos hepatologistas, no que respeita ao transplante de um doente cujo diagnóstico é polémico. Em uníssono, estes três elementos de especialidades diferentes reafirmam a voz da experiência que, como podemos verificar, tem um enorme peso na tomada de decisão.

$\mathrm{O} \mathrm{Dr}^{\circ}$ [coordenador da equipa de anestesia e intensivismo] às vezes vai porque temos uma ligação muito grande com ele. Vai e actua [...] eu acho que é um indivíduo óptimo! Tanto que chegou a ir a Cascais ver um doente meu, porque eu achava que aquele doente [...] Eu tenho uma espécie de sexto sentido, eu achava que aquele doente se safava, estava muito mal. E eu apresentei o doente, toda a gente olhou para mim como se eu fosse maluca, excepto o director. Todos! E o director disse "está bem, mas eu gostava que o $\operatorname{Dr}^{\circ}$ o visse, para ver a parte pulmonar". [...] E foi a casa dele e apoiou-nos "eu concordo consigo, eu acho que ele vai aguentar". E lá está, está óptimo. Foi de tal maneira [...] Ele tinha uma cirrose hepática alcoólica e estava mesmo nas lonas. [...] foi de tal maneira que o cirurgião disse "quem é que é o louco que mandou transplantar este doente”. [risos] [...] mas aguentou, está óptimo, o fígado aguentou. (HEPATOLOGISTA, 11)

Desta forma, fica expressa a importância de uma atitude interdisciplinar que é necessária por forma a conjugar os diferentes conhecimentos e olhares das várias especialidades médicas que, no seu conjunto, contribuem para o sucesso da transplantação hepática. No entanto, conjugar os diferentes conhecimentos, que se traduzem em discursos nem sempre fáceis de conciliar, conduz, em algumas situações, a conflitos.

A questão dos diferentes olhares sobre a mesma realidade é aqui colocada de uma forma clara. O hepatologista refere a produção do conhecimento médico como uma construção a partir de vários olhares e da forma diferente de questionar essa mesma realidade.

É assim, é tão importante eu tratar um doente, estar aqui a ver um doente, como é tão importante eu gastar o mesmo tempo a reflectir sobre o trabalho que fiz. Porque o reflectir leva depois à investigação, à pesquisa, a tentar perceber os erros. E da relação e do contacto e da discussão com outros colegas das outras especialidades é que, às vezes, nascem coisas. Porque nós, por vezes, contactamos pouco, e portanto as coisas vêm todas por escrito e às vezes há problemas de comunicação, digamos. 
A pessoa escreve uma coisa e pensa que está a transmitir outra, outro lê e pensa... compreende outra coisa e pronto, é fundamental. As reuniões multidisciplinares são uma parte do trabalho multidisciplinar. Quer dizer, eu ir-me sentar ao lado de uma anatomo-patologista a ver uma lâmina que ela já me descreveu "e não sei quê e tal e tu não achas que também podia ser isto". Porque, por muito objectivo que pareça ser uma lâmina, que é uma coisa que está ali a meter-se pelos olhos adentro, aquilo depende muito das hipóteses que se põem, a gente olha para as coisas duma maneira diferente. E, portanto, eu, às vezes, costumo dizer que nos relatórios que faço, costumo dizer a brincar que é para puxar pelo anatomo-patologista. Ponho hipóteses malucas para ele pensar, para ele estar a olhar para ali e pensar naquelas hipóteses e dizer "não isto não é, ou isto é" ou "isto pode ser", porque realmente são as coisas [...] deve haver sempre uma informação o mais circunstanciada possível, para a anatomo-patologista [...] para ele perceber o que a gente viu, o que a gente pensa daquilo tudo, para ver com esses olhos o que ele acha disso. (HEPATOLOGISTA, 13)

Reforça-se aqui um factor primordial para o sucesso do transplante hepático - a conjugação de vários olhares construídos a partir de conhecimentos diversos e específicos sobre uma mesma realidade. De facto, na transplantação hepática, tal como em outras áreas específicas da medicina, o conhecimento médico está repartido pelas diversas especialidades médicas que compõem a equipa. A estes vários fragmentos do conhecimento médico correspondem diferentes olhares sobre o doente e a doença, que operam dentro do seu campo de aplicação de forma autónoma. Deste modo, a capacidade de decisão encontra-se, também ela, fragmentada pelos diversos momentos do circuito de transplantação, em que cada uma das especialidades assume maior autonomia. Acresce que é nas zonas de fronteira destes conhecimentos que estes olhares divergentes assumem contornos de conflito, sobretudo quando estão presentes casos polémicos (Serra, 2006).

À grande especialização dos saberes médicos corresponde, necessariamente, uma maior restrição do olhar clínico. $\mathrm{Na}$ transplantação hepática, dada a exigência de conhecimentos muito especializados, os diferentes olhares são cada vez mais estreitos e, portanto, é menor a capacidade de observar o doente como um todo. Neste sentido, torna-se cada vez mais fundamental a conjugação com os restantes saberes. A interdisciplinaridade, sem a qual não é possível a construção do conhecimento global de transplantação hepática, constitui o grande mote de convergência de todos estes olhares, conhecimentos, técnicas, práticas e discursos médicos. 


\section{Conclusão}

$\mathrm{Na}$ transplantação hepática, o conhecimento e discurso médicos constituem tecnologias de poder por excelência. Estes dois elementos são construídos no quotidiano das práticas médicas, e a experiência clínica assume uma função primordial nessa construção. A utilização de um discurso científico acerca da doença, parece reforçar estratégias particulares que deixam adivinhar conflitos de interesses. Nestas interacções, os médicos trocam entre si informações técnicas específicas em torno dos casos clínicos. A partir do discurso utilizado, constata-se a existência de um monopólio de competências e conhecimentos especializados que sustentam a base do exercício da profissão médica e que se traduz no poder de tomar decisões concretas no que diz respeito ao percurso da doença.

Estamos, claramente, perante um serviço com uma componente técnica extremamente complexa, bem manifesta no modelo de produção dos cuidados médicos, verificando-se a coexistência de práticas médicas heterogéneas na produção dos cuidados, fruto da hiper-especialização médica existente no serviço. Esta complexificação da prestação dos cuidados, marcada por concepções e olhares distintos sobre a doença, valorizando-se ora a doença, ora um órgão em particular, ora as técnicas, é constantemente negociada através de um discurso científico que a justifica, coexistindo de uma forma dinâmica várias abordagens em torno do mesmo caso clínico.

Nas especialidades observadas, podemos constatar que a experiência clínica assume um papel central na construção e reprodução do conhecimento, relativamente a outros processos, tais como a investigação científica ou a apreensão de conhecimentos teóricos. A partir da prática clínica, os vários casos que se apresentam constituem importantes elementos a partir dos quais os médicos das várias especialidades recolhem informação e reconstroem esse conhecimento. Em termos de diversidade de patologias do fígado e tratamentos a elas aplicados, o conhecimento médico renova-se constantemente a partir das práticas médicas quotidianas. Mesmo assim, todas as especialidades consideram fundamental a componente de investigação, invocando a dificuldade em conciliar a investigação com a prática clínica, pelas características dos próprios hospitais e respectivos serviços, que influenciam as formas através das quais o conhecimento médico se reproduz. Neste sentido, a vocação desta unidade hospitalar, sobretudo ligada à prestação dos cuidados médicos e não à investigação, condiciona as formas de reprodução do conhecimento que é predominantemente construído na prática clínica da prestação dos cuidados médicos.

A experiência clínica é igualmente um factor que contribui para contornar os contextos de incerteza, i.e., o conhecimento construído a partir das 
práticas médicas legitima a acção e decisão médicas mesmo que, muitas vezes, contrarie o conhecimento teórico. Desta forma, o conhecimento médico produzido com base na experiência, a partir de casos concretos e individuais, apela para a natureza intuitiva da percepção da doença, independentemente da legitimidade do conhecimento científico.

\section{Referências bibliográficas}

Atkinson, Paul (1977), "The Reproduction of Medical Knowledge", in R. Dingwall et al. (orgs.), Health Care and Health Knowledge. London: Croom Helm; New York: Prodist, 85-106.

Atkinson, Paul (1981), The Clinical Experience: The Construction and Reconstruction of Medical Reality. London: Gower.

Atkinson, Paul (1995), Medical Talk and Medical Work. London: Sage.

Becker, Howard et al. (1961), Boys in White: Student Culture in Medical School. London: Transaction Publishers.

Berger, Peter; Luckmann, Thomas (1967), The Social Construction of Reality. Garden City: Doubleday Anchor Books.

Foucault, Michel (1963), Naissance de la clinique. Paris: Gallimard.

Freidson, Eliot (1984), La profession médicale. Paris: Payot.

Freidson, Eliot (1986), Professional Powers. Chicago: The University of Chicago Press.

Freidson, Eliot (1987), Professionalism, Empowerment and Decision-Making. (Position paper written for the National Education Association). Disponivel em: http://itsa. ucsf.edu/ eliotf/Professionalism,_Empowerme.html.

Keating, Peter; Cambrosio, Alberto (2003), Biomedical Platforms: Realigning the Normal and the Pathological in Late Twentieth-Century Medicine. Cambridge, Mass.: MIT Press.

Mol, Annemarie (2002), The Body Multiple: Ontology in Medical Practice. Durham: Duke UP.

Serra, Helena (2006), "Da tecnologia à tecnocracia. Estratégias de poder médico no limiar das fronteiras entre especialidades: o caso da transplantação hepática", in Graça Carapinheiro (org.), Sociologia da Saúde. Estudos e perspectivas. Coimbra: Pé de Página Editores.

Turner, Brian (1995), Medical Power and Social Knowledge. London: Sage. 